\title{
UN DEPÓSITO RITUAL TARDO-PÚNICO DE PEQUEÑOS VASOS FRENTE A LA PLAYA DES CODOLAR (IBIZA)
}

\author{
A LATE-PUNIC RITUAL DEPOSIT OF SMALL VESSELS IN \\ FRONT OF THE CODOLAR BEACH (IBIZA)
}

\author{
JOAN RAMON TORRES*
}

Resumen: En este trabajo se presenta y estudia un conjunto de vasos, todos ellos de fabricación ebusitana, recuperados de modo casual en la década de los 1980 cerca de la costa meridional de Ibiza. Su cronología, totalmente homogénea, se sitúa en pleno siglo II a.C. Por otro lado, resalta el carácter peculiar en la elección de los tipos y la composición final del conjunto, que no encuentra parangón, ni en los ajuares funerarios, ni en horizontes de hábitat u otro tipo de esta época. Por este hecho, y por el carácter reducido de las piezas, en algunos casos claramente miniaturas, debe ser interpretado como un conjunto ritual. Su situación aislada, aunque en un marco de amplia colonización agrícola, pone en evidencia un tipo de actividad cultual hasta la fecha desconocida en la Ibiza púnica. Palabras Clave: Depósito ritual, cerámica ebusitana, época tardo-púnica, colonización agrícola.

\section{LUGAR, CARACTERÍSTICAS Y CIRCUNSTANCIAS DEL HALLAZGO}

Se trata de un hallazgo realizado de modo casual, en los años 1980, a raíz de labores de remoción de tierras en el jardín de una casa moderna en la antigua finca de can Toni Margalit, colindante con las denominadas can Parot y can Verger, que se ubica frente a la playa des

* Consejo Insular de Ibiza / Departamento de Patrimonio Histórico. Av. España 49, 07800 Ibiza. Correo-e: joanramontorres@gmail.com

\begin{abstract}
This paper presents the study of seven small-sized Ebusitan vases that were found by chance near the Southern shore of Ibiza some thirty years ago. They are dated to the second century BC. The composition of this group of vases is extremely peculiar, very different from the associations attested in both funerary and habitation contexts. This adds to the small -even miniature- size of the vases to suggest a ritual character. The find indicates therefore a sort of previously unknown cultic activity that should be linked to the agricultural colonization of Ibiza.

Key words: Ritual deposit, ebusitan ceramic, late-Punic period, agricultural colonization.
\end{abstract}

Codolar (vénda -nombre local para designar distintas demarcaciones territoriales- des Recó, término municipal de Sant Josep de sa Talaia, Ibiza) (figs. 1 y 2), junto al margen septentrional de la carretera que une el aeropuerto de Ibiza con la Cova Santa.

El área se inserta en un terreno prácticamente llano, a 14 m s.n.m., cuyo entorno circundante, atravesado por el torrente de can Font, que cruza el área en dirección NE-SO, para desembocar en la playa citada, se hallaba tradicionalmente dedicado a cultivo de secano, con alternancia de algunos espacios de regadío. 


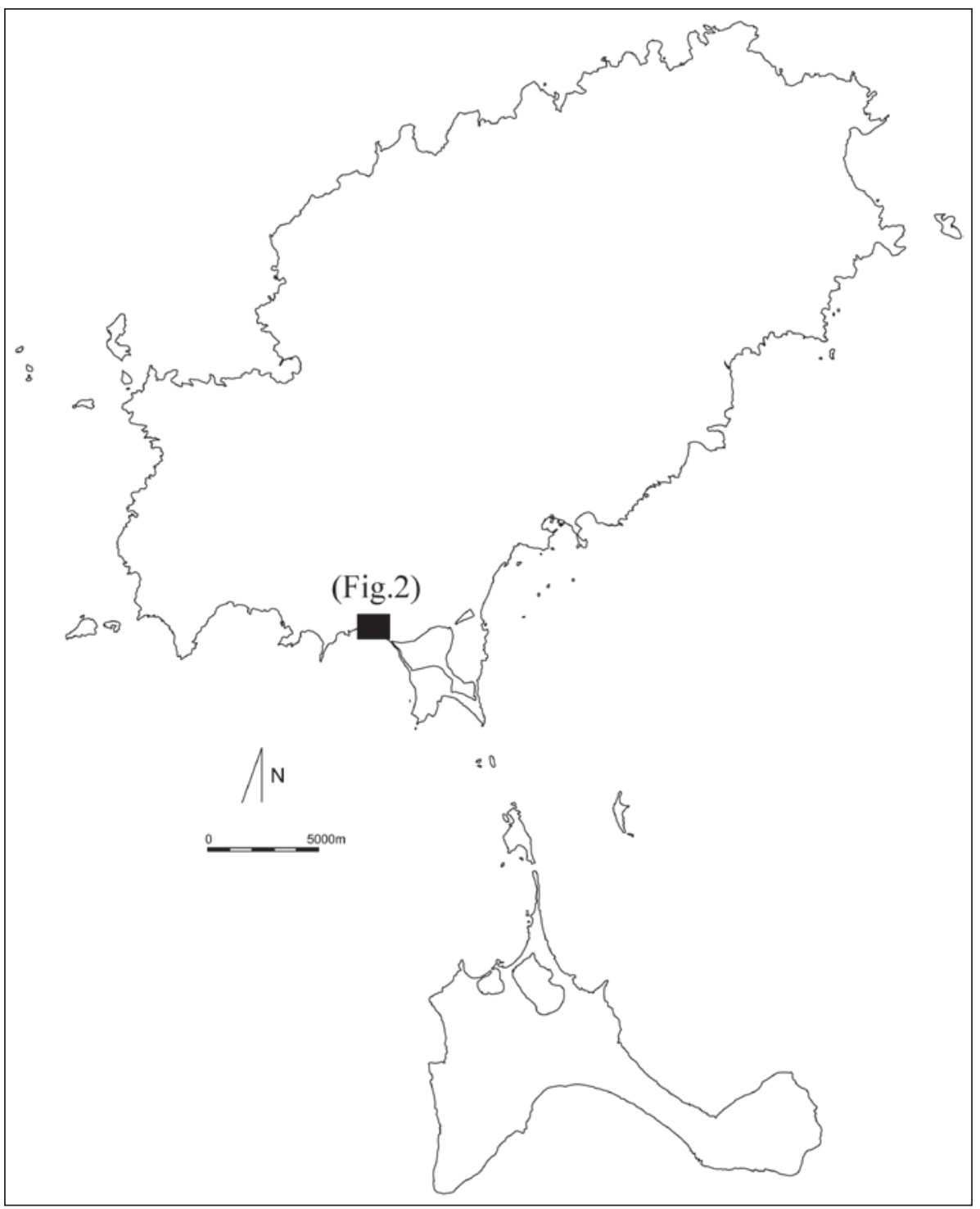

Figura 1. Mapa de Ibiza y Formentera, en recuadro negro, el área de la fig. 2.

A partir de informaciones orales facilitadas por su descubridor, cabe deducir que se trataba de una pequeña cista enterrada en el subsuelo a escasa profundidad y compuesta de cuatro losas aplanadas de piedra caliza local, sin retoques especiales, colocadas en vertical. En su interior aparecieron los elementos cerámicos que se presentan y estudian a continuación.

Aunque no fue percibido en el proceso de exhumación, los materiales hallados y conservados al parecer en su totalidad, reflejan un detalle a tener en cuenta y es que los vasos debían hallarse en el interior de la cista colocados en posición vertical, única explicación posible al hecho que una serie de fracturas recientes, que en buena parte presentan, acusan golpes de azada únicamente en sus partes superiores. Naturalmente, si además existía algún género de orden en la deposición, es algo que se ignora por completo. Otro dato, a tenor de algunas fracturas antiguas, es que una parte de las piezas fue, casi con seguridad, enterrada en estado de mutilación y, además, algunas de ellas presentan claras trazas de quemado, concretamente zonas ennegrecidas, por acción directa de fuego o brasas. En cambio, ninguno de los picos de las lucernas presenta el mínimo indicio de uso.

No hay pues detalles de estratigrafía, ni tampoco ningún dato gráfico, aunque de las citadas informaciones y de un examen superficial del terreno, realizado por quien suscribe, podría derivarse la posibilidad de 


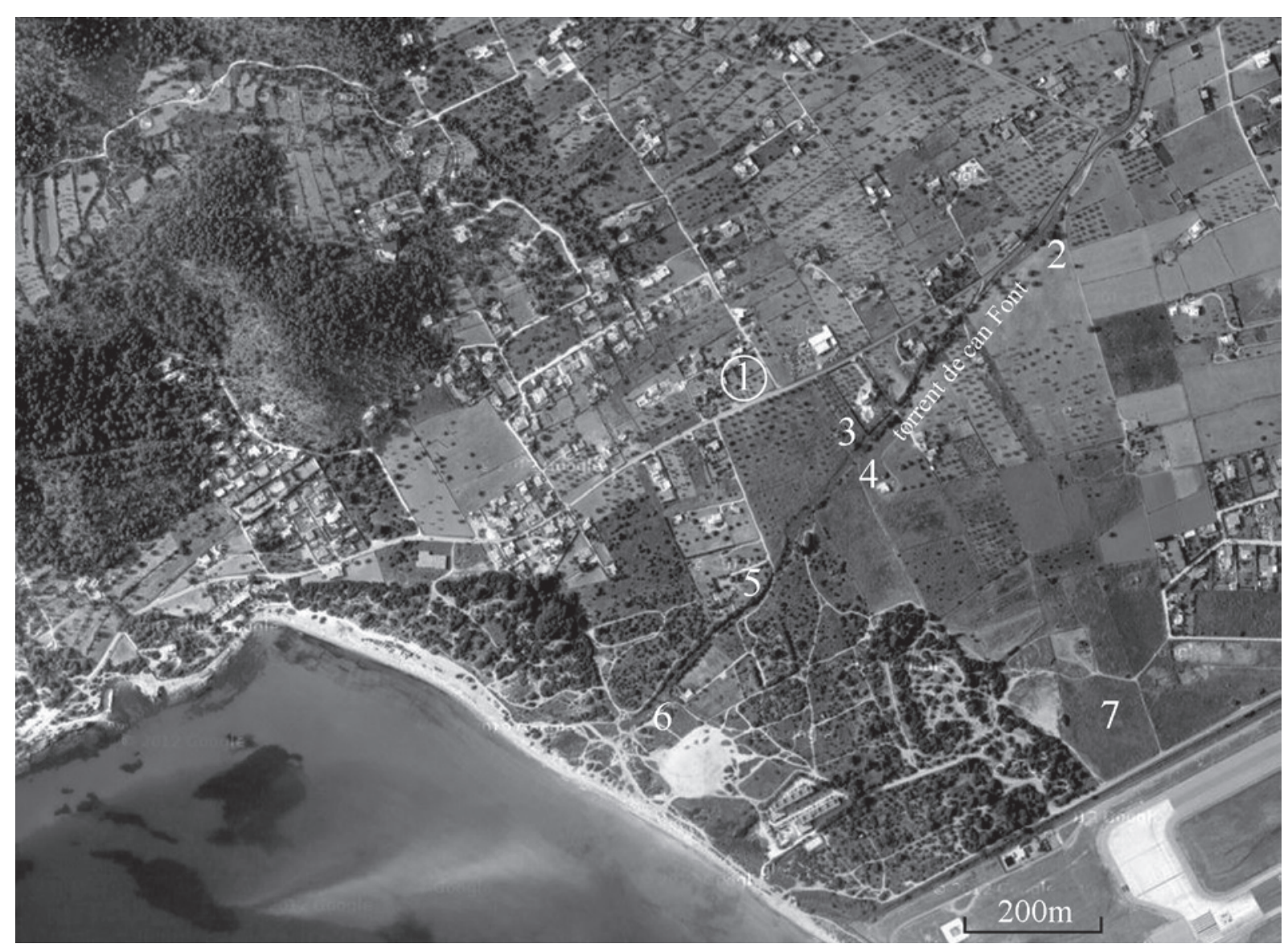

Figura 2. 1 (en un círculo) can Margalit, lugar del depósito, 2 yacimiento H5-03 (can Perot), 3 yacimiento H5-06 (can Recó-1), 4 yacimiento H5-05 (can Joan Pamina), 5 yacimiento H5-07 (can Recó-2), 6 yacimiento H5-08 (ca n’Albercoc), 7 yacimiento H5-11 (can Ribes-2).

que en su proximidad inmediata no existan otros elementos arqueológicos.

Por sus características, y aún sin el apoyo de otros elementos de juicio, es evidente que se trata de un pequeño depósito ritual o cultual, cuya cronología es el siglo II a.C., por tanto de época púnica tardía. Lo peculiar de este depósito, que por ahora puede considerarse ejemplo único en el ámbito púnico-ebusitano, hace interesante, bajo diversos puntos de vista, su estudio y presentación.

\section{LOS MATERIALES}

Los dibujos a lápiz de los materiales -que permanecen en manos de su descubridor- fueron realizados por J. M. López Garí y han sido digitalizados por el autor del presente trabajo, que lo es también de las fotografías (figs. 3 a 6 ).

\subsection{Lucernas}

1. Completa, excepto una fractura parcial en el pico izquierdo. Base aplanada y levemente marcada por el exterior, cortada a cuerda. Longitud total $8,2 \mathrm{~cm}$, anchura máxima $6,2 \mathrm{~cm}$, altura máxima $3,5 \mathrm{~cm}$, pasta color marrón rojizo (figs. 3, 4 y 6).

2. Completa, excepto fracturas parciales en su parte superior. Base aplanada y bien marcada por el exterior, con perfil rectilíneo. Longitud total $8 \mathrm{~cm}$, anchura máxima $7 \mathrm{~cm}$, altura máxima $3,1 \mathrm{~cm}$. Pasta color marrón rojizo (figs. 3,4 y 6).

3. Casi completa en su longitud, pero con mutilaciones importantes recientes en su parte superior y en los extremos de los picos. Base cortada a cuerda, aplanada y levemente marcada por el exterior. Longitud conservada $7,3 \mathrm{~cm}$, anchura máxima conservada $4,8 \mathrm{~cm}$, altura máxima $2,9 \mathrm{~cm}$. Pasta color marrón (figs. 3 y 6). 


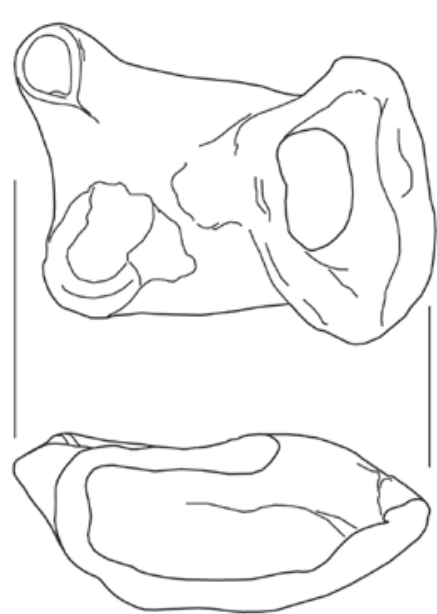

1

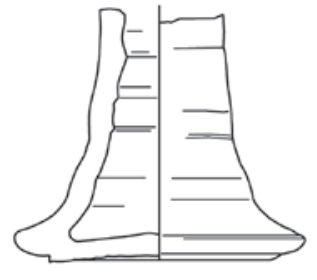

4
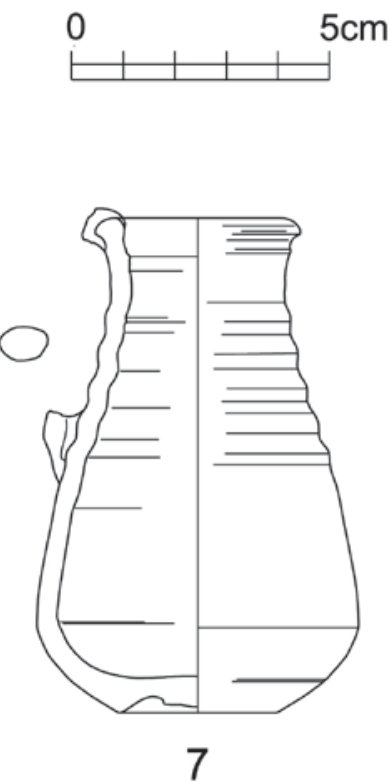

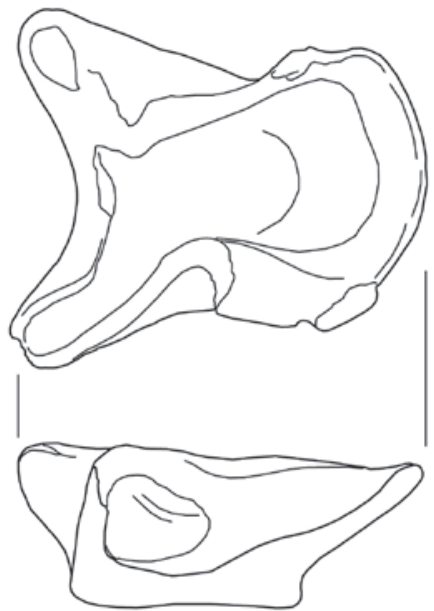

2

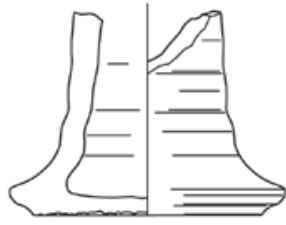

5

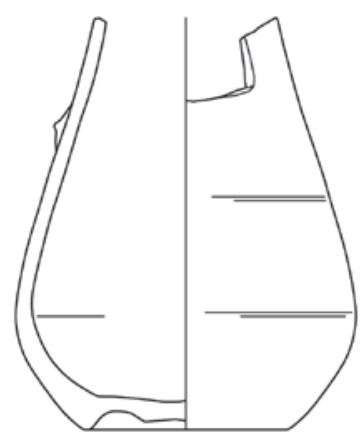

8

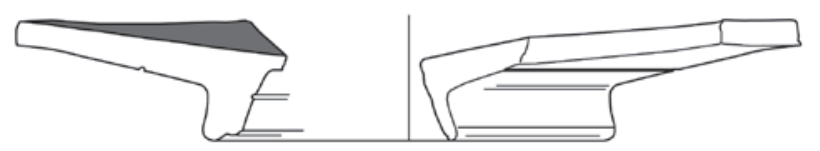

10
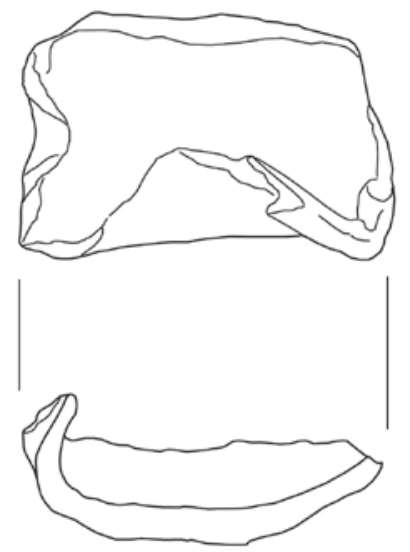

3

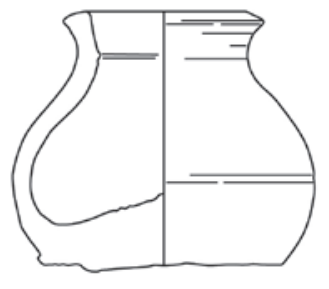

6

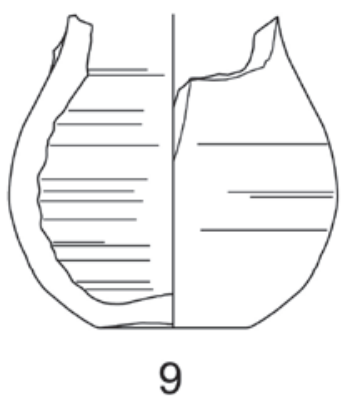

9

Figura 3. Conjunto de vasos. 

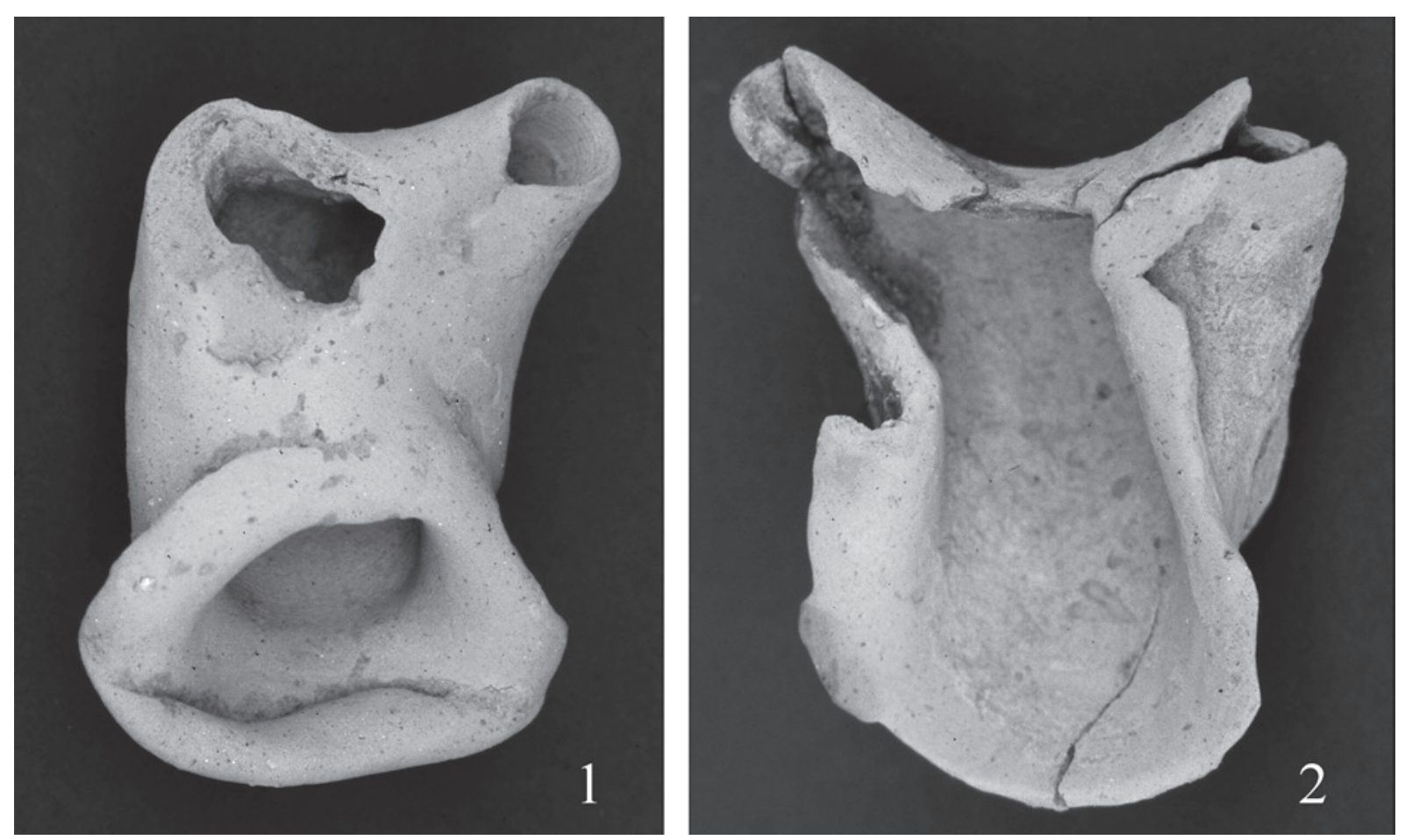

Figura 4. Lucernas núm. 1 y 2.

Las tres piezas son del mismo tipo, un modelo que constituye el estadio final de la evolución formal de las famosas lucernas fenicio-púnicas de doble mechero. Corresponden todas ellas al tipo 10.4 de Rodero (1980: figs. 2 y 35 núm. 4-9), equivalente al E.1.I.1 de Guerrero (1999: fig. 116).

Tienen una clara inspiración en modelos del norte de África central -muy especialmente cartagineses- del tipo Merlin y Drappier 61 (1909), Cintas 10-13 (1950: pl. XL-XLI y XCIX), Deneauve IX (1969: 37-38, pl. XXIII, 99, 104), Bussière III a (1989: 51, fig. 1 y 13). Representadas en la fase final de las necrópolis de la capital norteafricana, existen igualmente en los niveles de destrucción de la ciudad del 146 a.C. (Ferron y Pinard 1960-1961: pl. LVII, 345-348; Lancel 1982: 89, fig. 105, del nivel de incendio A.152).

Aunque las lucernas cartaginesas de este tipo no presentan nunca un tramo tan largo en la parte completamente cerrada, dejando incluso las junturas de los pliegues más visibles -hecho que las distingue de las ibicencas-, es obvio que son su fuente de inspiración. Por tanto, un caso más que añadir a la lista de influencias morfológicas cartaginesas directas sobre la producción cerámica púnico-ebusitana, bien atestiguada en otros tipos de vasos ibicencos desde el siglo VI a.C. hasta la destrucción de la metrópolis (recogiendo otra bibliografía, Ramon 2012a: 583, 2012b: 226-237). También es interesante observar cómo, excepción hecha de Cartago e Ibiza y de algunos materiales de este tipo conservados en los museos de Philippeville y Constantina (Bussière 1989: 51), este modelo tan evolucionado de lucerna púnica no se conoce, en estricto, más al oeste de Argelia oriental. En cuanto a Sicilia y Cerdeña este tipo parece también ser inexistente.

En la propia Ibiza, hasta la fecha, eran conocidas casi exclusivamente en las necrópolis, donde su número tampoco es excesivamente alto. De la necrópolis del Puig des Molins cabe citar una pieza en el hipogeo 13 de la campaña de 1904 (Fernández 1988: fig. 3.10), que presenta distintas fases en enterramientos, una del siglo $\mathrm{V}$ a.C. $y$ otras enmarcadas entre los siglos II-I a.C. o incluso algo más tarde. Y también otras de las campañas de C. Román, cuyo contexto en general resulta ambiguo (Fernández 1992: cat. 126 -1921-SC-, 661 -1921-SC-, 844-1924 zanjas-, 1062 -1928-SC-, 1175 -H15-1929-, 1126-H6-1929), lo mismo que las exhumadas en la campaña de 1946 (Gómez 1984: figs. 7, 3 y $5-\mathrm{H} 2-, 35,1-2-\mathrm{H} 26-, 43,2-\mathrm{F} 41)$. Seguramente, las piezas del Museo Arqueológico Nacional publicadas por Rodero (1980: fig. 2 y 35 núm. 4-9) provienen 


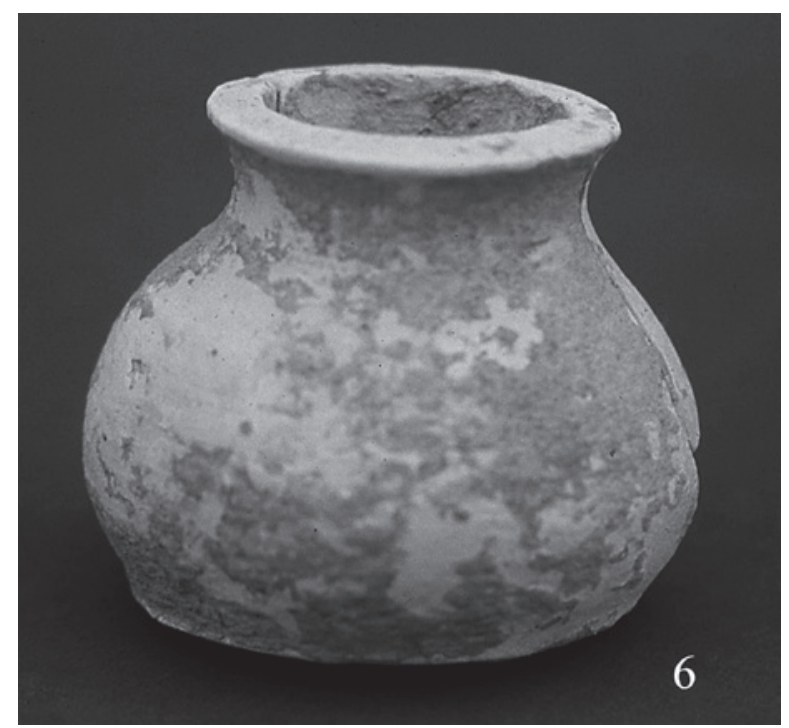

Figura 5. Vaso núm. 6.

mayoritariamente de Puig des Molins. A ellas cabría añadir otro ejemplar, igualmente sin contexto definido de la necrópolis rural de sa Barda (Tarradell y Font 2000: lám. XXVII, SB16). Finalmente, cabe citar una pieza del estrato 1 del edificio 7-14-15 de Na Guardis (Guerrero 1997: fig. 121, 3), que evidentemente se halla ligada al último momento de ocupación ebusitana del islote, avanzado el siglo II a.C.

Así pues, por una parte, los mismos prototipos cartagineses ilustran una cronología de la primera mitad o segundo cuarto del siglo II a.C. y, por otra, en el caso de las ebusitanas, los datos directos van en el mismo sentido.

\subsection{Posibles pebeteros de pie alto}

4. Conserva solo la base. Altura total conservada 4,9 $\mathrm{cm}$, diámetro de la base $5,7 \mathrm{~cm}$. Pasta color marrón anaranjado (figs. 3 y 6 ).

5. Altura total conservada $3,9 \mathrm{~cm}$, diámetro de la base $5,4 \mathrm{~cm}$. Pasta color marrón anaranjado (figs. 3 y 6).

A pesar que ambas piezas se hallan reducidas a la base, conservando sólo un tramo de la parte baja del pie, parece evidente que son pebeteros sobre pie alto columnar y cazoleta superior simple. Se trata de elementos desconocidos casi por completo en el repertorio vascular ebusitano.

Aún con serias dudas, en cuanto a su semejanza, sólo puede traerse a colación una pieza procedente del hipogeo 35 de la campaña de 1946 en el Puig des
Molins (Gómez 1984: 95-98, fig. 42.3). Sin embargo, en este caso, el vástago es mucho más macizo, por lo cual podría ser un soporte, pues la cazoleta superior está perforada igual que el fondo inferior. Junto con este elemento fueron hallados vasos del siglo V a.C. y otros de principios de época imperial romana; solo un ungüentario de tamaño grande podría ser del siglo II o incluso del I a.C., no siendo por el resto segura su correspondencia con la pieza analizada.

Las dos piezas de can Margalit se integran claramente en un conjunto del siglo II a.C., además, su fondo externo, cortado a cuerda, igual que otros vasos, parece también típico de este momento.

\subsection{Pequeño vaso cerrado}

6. Fue anteriormente publicado en otro trabajo (Ramon 2012a: 604, fig. 12 núm. 107). Se conserva completo. Borde exvasado de sección triangular, sobre cuello embrionario. Tiene una base con mucho espesor de pared, sobre todo en su parte central, más ancha que el borde y cortada groseramente a cuerda. Altura total $5 \mathrm{~cm}$, diámetro del borde 3,9 $\mathrm{cm}$, diámetro máximo $5,9 \mathrm{~cm}$, diámetro de la base $4,7 \mathrm{~cm}$. Pasta color beige, parcialmente quemado (figs. 3, 5 y 6).

En la propia Ibiza los paralelos estrictos a este tipo son escasos y, en general, son más bien formas aproximadas, con el perfil en S más atenuado, procedentes de la necrópolis del Puig des Molins (Fernández 1992: cat. 346, 801 -H13-1924, 1040 -1926 zanjas). Lo mismo puede decirse de un individuo del compartimento 3 de Na Guardis (Guerrero 1984 a, fig. 88, 5), fechable probablemente en el siglo II a.C.

\subsection{Jarritos de un asa sobre el borde}

7. Conserva el cuerpo completo, le falta solo una parte del asa, con fractura antigua que, sin embargo, mantiene ambos arranques. Borde redondeado, acanaladuras de torneado bien marcadas en la mitad superior externa. Fondo rehundido con acanalación ancha. Altura total del cuerpo $9,6 \mathrm{~cm}$, diámetro del borde $4 \mathrm{~cm}$, diámetro máximo $6,2 \mathrm{~cm}$, diámetro de la base $3 \mathrm{~cm}$. Pasta color marrón anaranjado, parcialmente quemado (figs. 3 y 6 ).

8. Conserva los tres cuartos inferiores del cuerpo, con la impronta del arranque inferior del asa. Perfil 


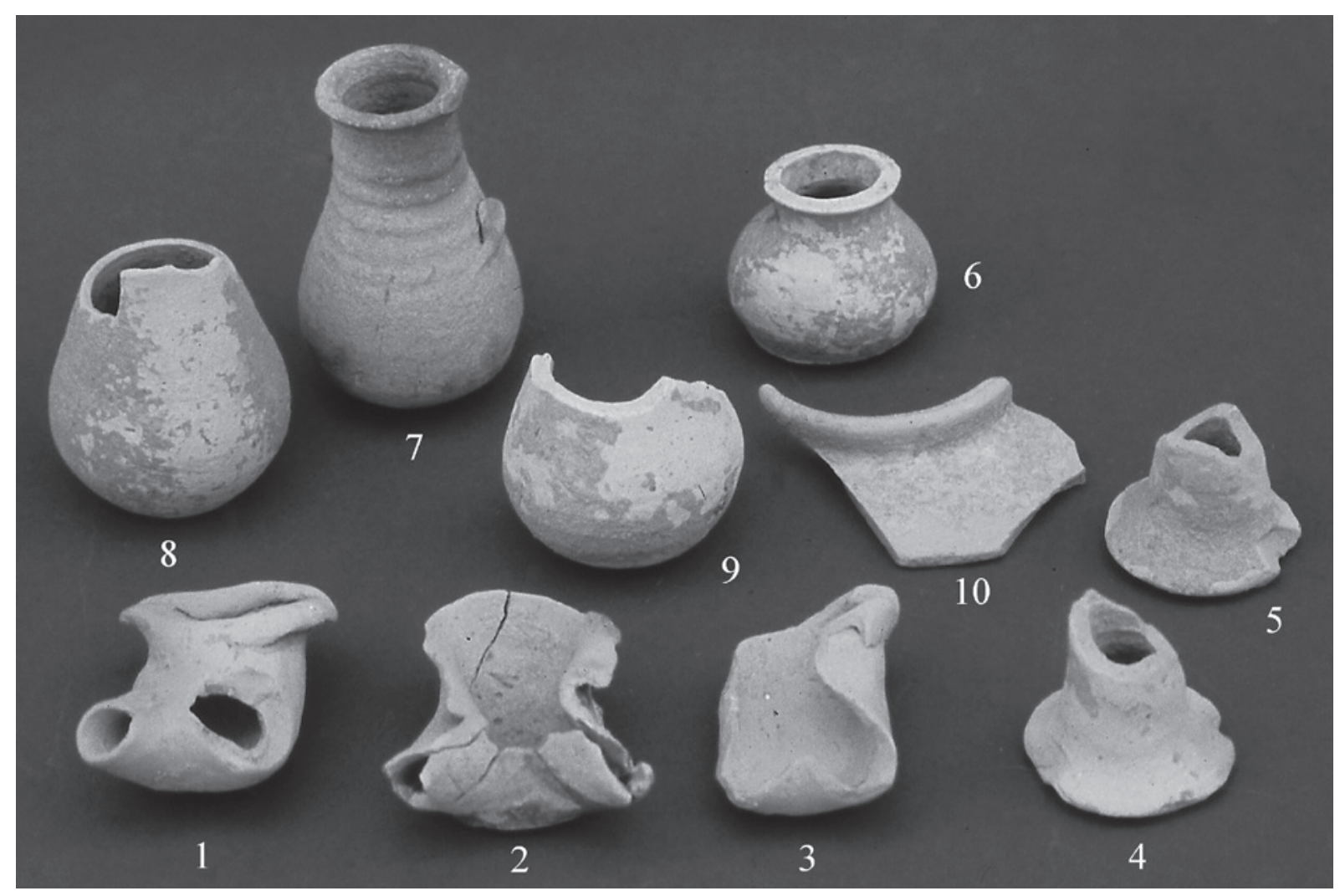

Figura 6. Conjunto de vasos.

piriforme. Fondo rehundido con acanalación ancha Altura total conservada $8 \mathrm{~cm}$, diámetro máximo 6,6 $\mathrm{cm}$, diámetro de la base $3,9 \mathrm{~cm}$. Pasta color marrón rosado, parcialmente quemado (figs. 3 y 6).

9. Conserva poco más de la mitad inferior del cuerpo, con la impronta del arranque inferior del asa. Cuerpo inferior de perfil esferoide, que da paso a un cuello presumiblemente cónico. Base con fondo externo levemente rehundido, sin acanaladura. Altura total conservada $6,1 \mathrm{~cm}$, diámetro máximo $6,4 \mathrm{~cm}$, diámetro de la base $2,9 \mathrm{~cm}$. Pasta color marrón anaranjado, parcialmente quemado (figs. 3 y 6).

Todos ellos pertenecen al tipo Eb.13 c (Fernández 1992: 21; Fernández y Costa 1998: 31, fig. 9), B.1.III.3 de Guerrero (1999: fig. 56), tratándose de un modelo del cual existen algunos similares en la bibliografía. Por una parte, en Puig des Molins (Fernández 1994: cat. 285 -de una fosa de la campaña de 1922-, 556, 639 1923-SC, 813 -hipogeo 14 de 1924-, 850 - SC-1924-, 851 -SC-1924-, 795 -hipogeo 11 de 1924- 1043 -fosa 3 fr 1928-, 1207 -fosa 5 de 1929-, hipogeos 45 (Gómez 1984: fig. 52.4) y 50, (ibd.: fig. 55.3) de la campaña de 1946, conociéndose otras piezas sin contexto en colecciones extrainsulares (Tarradell y Font 1976: núm. 43; Guerrero 1984b: núm. 5). A ellos cabe añadir al menos una pieza de una necrópolis en Sant Agustí (Tarradell y Font 2000: XXI SA 13).

Sin embargo, la mejor información contextual por ahora publicada procede de diversos estratos del asentamiento ebusitano de na Guardis, concretamente en el nivel II del fondeadero N (Guerrero 1984a: fig. 19.1-4), donde algunos ejemplares -al igual que los del presente depósito- tienen acanalación ancha en el fondo externo. Se documentan piezas de este tipo, además, en el nivel de abandono de la habitación 2 (Guerrero 1984a: fig. 56.1-4), en el sector exterior este (Guerrero 1984a: fig. 81.5), con fechación difusa, en el compartimento 3 (Guerrero 1984a: fig. 88, 4), probablemente del siglo II a.C., en el espacio entre muros 8,7 y 14, estrato II, del edificio B (Guerrero 1997: fig. 80.9) del último cuarto del siglo III a.C., pero con base rehundida simple y sólo cuerpo inferior, con diámetro más bien alto y en el estrato 1, superficial, del edificio 7-14-15 (Guerrero 1997, fig. 116.15-15). Existe además en el yacimiento también mallorquín de la Playa des Trenc 
(Guerrero 1997: fig. 196.1-4), en la zona denominada la explanada, junto con materiales que tienen un lapso cronológico amplio que va entre el siglo IV y I a.C. Sin abandonar esta isla cabe también mencionar un ejemplar completo del Turó de ses Beies (Camps, Vallespir 1998: fig. 78, 8/10).

Por lo explicado antes y por otros datos inéditos, es evidente que la cronología de este tipo de jarrito se centra en pleno siglo II a.C. y no se conocen especímenes que claramente correspondan a este tipo en horizontes del siglo III a.C. y en cuanto a una eventual continuidad en el I a.C., de momento, tampoco hay pruebas concluyentes.

\subsection{Plato de imitación campaniense}

10. Se conserva únicamente un fragmento, con fractura antigua, correspondiente a la base anular y a la parte inferior del perfil. Diámetro de la base $8 \mathrm{~cm}$, altura máxima conservada $2,4 \mathrm{~cm}$. Pasta color marrón, con restos de pintura rojiza (fig. 3).

Corresponde a una versión ebusitana -tipos 2234c, 2234a, 2252 de Morel- de la Campaniense A, enmarcado en el tipo 3.6 de Rodero (1980: fig. 2 y 24.4), equivalente al A.1.II.5.b de Guerrero (1999: fig. 15). Es un modelo abundantísimo en Ibiza, ampliamente exportado a las Baleares, cuya cronología discurre a lo largo de todo el siglo II, con posible perduración en la primera mitad del I a.C. (Ramon 2012a: fig. 13, 119, 120, 121, recogiendo bibliografía anterior).

\section{INTERPRETACIÓN Y CONTEXTUALIZACIÓN HISTÓRICO-ARQUEOLÓGICA}

El conjunto vascular estudiado se fecha claramente en el siglo II a.C., muy probablemente en sus dos primeros tercios, según ya se ha visto en el estudio individualizado de los materiales que, sin excepción y de modo coherente, coinciden en esta cronología.

En cuanto al carácter del hallazgo, todo apunta a que se trata de un depósito ritual ligado probablemente a algún acto de culto. Es cierto que elementos como los jarritos Eb.13c, las lucernas, la vajilla de imitación campaniense e incluso -aunque mucho menos frecuentemente en este caso- pequeños vasos como el núm. 6, están representados en las necrópolis ebusitanas, pero nunca formando una agrupación de estas características. Por otro lado, mucho más raros en dichas necrópolis son los pebeteros o timyatheria vasculares, sean de cazoleta simple o doble, estos últimos, en cambio, con presencia muy significativa en el santuario de es Cuieram (Ramon e.p.). En este mismo sentido, tampoco ningún dato de los recogidos oralmente de parte de su descubridor hace ni tan solo sospechar la presencia de una tumba.

Completamente descartada, a todos los niveles, puede considerarse también cualquier interpretación del depósito como resultado de una actividad doméstica, en cuyo ámbito tal combinación es imposible y faltan, excepción hecha del plato, todos los componentes típicos. De otro lado, en contextos de esta clase, ya no solo son rarísimos los pebeteros, sino también incluso las lucernas, más aún las de morfología púnica, que en cambio aquí, proporcionalmente, se hallan muy bien representadas.

Por otra parte, también el reducido tamaño de todas las piezas, que en algunos casos, como el vaso 6, puede considerarse miniaturización y el carácter global del combinado, encuentran una lógica más acorde con un depósito ritual. Cabe indicar que elementos cerámicos claramente miniaturizados fueron también depositados en el santuario ibicenco de es Cuieram (Ramon e.p.: núm. 62, 94, 132-133, 141), igual que sucedió en otros lugares de culto fuera de la isla (Bartoloni 1992, De La Genière 2008).

Ya se ha dicho al principio que el examen del conjunto de vasos refleja en algunos casos mutilaciones previas y en otros, trazas de quemado, hecho que hace pensar en algún tipo de ritual previo a su inhumación. Sin embargo, al no haberse realizado excavaciones arqueológicas de ninguna clase en el lugar del hallazgo casual ni en su entorno inmediato, no existe por ahora ningún otro dato para una contextualización amplia, de modo que es imposible saber si fue un depósito aislado o, por el contrario, tuvo lugar en el marco de un establecimiento doméstico-industrial o incluso en un lugar específico de culto.

En este sentido, conviene recordar que en puntos diversos del mundo rural púnico-ebusitano el hallazgo de pequeñas concentraciones de figuras de terracota ha propiciado una rica literatura sobre los cultos en este ámbito, aunque en ninguno de los casos ha quedado claro si tenían lugar en espacios diferenciados, independientes y más o menos separados de los núcleos habitados o por el contrario integrados en estos. En cambio, en el edificio A de ses Païsses de cala d'Hort es evidente que dicho culto se hallaba incorporado, de un modo u otro, en las dependencias de la instalación rural, cuyas funciones básicas eran la producción 
y almacenamiento industrial agrícola, junto con el hábitat (Ramon 1995: 53-54).

Con toda lógica, los autores que han tratado el tema han dudado a la hora de poner nombre a la situación y así se ha hablado de templos, santuarios, capillas, etc., en lugares como el Puig d'en Valls, can Pis, can Jai y ca n'Úrsul, que se reparten a lo largo y ancho de la geografía insular (Gómez 2008: 125-127, recogiendo bibliografía anterior). El común denominador es tratarse de datos del primer cuarto del siglo XX -cuando la preocupación por los análisis arqueológicos integrados era muy escasa, igual que el aparato gráfico y literario que acompañaba las correspondientes publicaciones-y su base, el hallazgo de figuras de terracota, de modo descontextualizado estratigráficamente hablando, aunque formando pequeñas concentraciones desde el punto de vista espacial. El depósito estudiado se encuentra a tan sólo 1,5 km en dirección E del yacimiento de ca n'Úrsul (Tarradell y Font 2000: 129-130), antes mencionado, pero se halla fuera de cuestión conjeturar cualquier tipo de vínculo directo.

Otro aspecto, que automáticamente se deriva de todo lo anteriormente explicado, es la imposibilidad de saber a qué tipo de culto, y eventualmente a qué divinidad fue dedicado el depósito estudiado. Lo mismo en cuanto a las razones que motivaron la elección de este punto para la inhumación del conjunto de objetos. En todo caso, sí conviene recordar que el lugar (figs. 1 y 2) se halla a $600 \mathrm{~m}$ al $\mathrm{N}$ de la línea actual de la playa des Codolar, pero todo indica que originalmente la distancia era aún menor. Se halla igualmente a $170 \mathrm{~m}$ de distancia en dirección $\mathrm{N}$ del torrente de can Font y en un área inmediata a las salinas de Ibiza, frente a un paisaje marítimo-terrestre de remarcable belleza, a la vista directa de Formentera, los islotes de es Freus y el espectacular monte acantilado sobre el mar, conocido como Cap des Falcó, que constituye la punta meridional de Ibiza.

Nada de lo observado sobre el terreno hace pensar en un establecimiento en el mismo lugar, aunque in extenso, en épocas púnica y romana, se trataba de un área poblada. En efecto, los datos actuales, en parte reflejados en las cartas arqueológicas, elaboradas a principios de los años 90 por las autoridades autonómicas, registran asentamientos a ambos lados del cauce del torrente de can Font (fig. 2), que en general presentan indicios en superficie de ocupación, desde los siglos IV-III a.C., hasta distintos momentos de la época imperial romana, siendo el II a.C. el mejor representado, aunque ninguno de ellos ha sido objeto de excavaciones. Es muy probable, por tanto, que el depósito ritual fuera obra de los habitantes de alguno de estos enclaves agrícolas.
Si a pesar de ello se enterró en un punto aislado, se explicaría en cierta forma la rareza de hallazgos de este tipo, puesto que las excavaciones normalmente se han realizado en o alrededor de los asentamientos, incluida las necrópolis. Cabe pensar que no fue un caso único, pero su significado concreto permanece por ahora en el misterio.

\section{Agradecimientos}

Trabajo enmarcado en el proyecto HAR2012-36500, financiado por el Ministerio de Economía y Competividad y el grupo de investigación CIVITAS del área de Historia Antigua de la Universitat de Balears.

\section{BIBLIOGRAFÍA}

Bartoloni, P. (1992): "Ceramiche vascolari miniaturistiche dal tophet di Sulcis". Quaderni della Soprintendenza Archeologica per le Province di Cagliari e Oristano 9: 141-155.

Bussière, J. (1989): "Les lampes phénicopuniques d'Algérie". Antiquités africaines 25: 41-68.

Camps, J. y Vallespir, A. (1998): Excavacions a Santa Ponça. Mallorca. El turó de les Abelles. La deixa 1. Monografies de Patrimoni Històric. Palma, Consell Insular de Mallorca.

Cintas, P. (1950): Céramique punique. Publications de l'Institut des Hautes Études de Tunis, vol. III. París, Libraire C. Klincksieck.

De La Genière, J. (2008): "Céramique offerte à la divinité", en Doni agli Dei, Università degli Studi di Napoli Federico II: 13-22. Nápoles, Naus.

Deneauve, J. (1969): Lampes de Carthage. Centre National de la Recherche Scientifique, Série Archéologie 505. París, Centre de Recherches sur L'Afrique Méditerranéenne.

Fernández, J. H. (1988): "Un exponente de la reutilización de los hipogeos en el Puig des Molins: el hipogeo no 13 de la campaña de 1.904", en E. Acquaro y S. Pernigotti (a cura di), Studi di Egittologia e di Antichità Puniche: 121-155. Pisa, Ist. Editoriali e Poligrafici, Pisa.

Fernández, J. H. (1992): Excavaciones en la necrópolis del Puig des Molins (Eivissa). Las campañas de D. Carlos Román Ferrer: 1921-1929. Trabajos del Museo Arqueológico de Ibiza 28-29. Museo Arqueológico de Ibiza. 3 vol. Ibiza, Museu Arqueològic d'Eivissa i Formentera. 
Fernández, J.H. y Costa, B. (1998): “La cerámica común púnico-ebusitana: precisiones tipológicas y cronológicas sobre algunas formas cerradas", en Misceláneas de arqueología ebusitana I, Treballs del Museu Arqueolòic d'Eivissa i Formenter, 42: 23-81. Ibiza, Museu Arqueològic d'Eivissa i Formentera.

Ferron J. y Pinard M. (1960-1961): "Les fouilles de Byrsa". Cahiers de Byrsa IX: 77-170. París, Imprimerie Nationale.

Gómez, C. (1984): La necrópolis del Puig des Molins (Ibiza). Campaña de 1946. Excavaciones Arqueológicas en España 132. Madrid, Ministerio de Cultura.

Gómez, C. (2008): "Espacios sagrados en la Ibiza púnica”, en X. Dupré, S. Ribichini y S. Verger (coord.), Saturnia Tellus: definizioni dello spazio consacrato in ambiente etrusco, italico, fenicio-punico, iberico e celtico, Atti del convegno internazionale: 119132. Roma (2004), Roma, Consiglio Nazionale delle Ricerche.

Guerrero, V. M. (1984a): Asentamiento púnico de na Guardis. Excavaciones Arqueológicas en España 133. Madrid, Ministerio de Cultura.

Guerrero, V. M. (1984b): "Materiales arqueológicos del legado Mulet en la Sociedad Arqueológica Luliana". Boletín de la Sociedad Arqueológica Luliana XL: 39-76.

Guerrero, V. M. (1997): Colonización púnica de Mallorca. La documentación arqueológica y el contexto histórico. Palma de Mallorca, El Tall.

Guerrero, V. M. (1999): La cerámica protohistórica a torno de Mallorca (s. VI-I a.C.). BAR international Series 770. Oxford, John and Erika Hedges Ltd.

Lancel, S. (1982): "L'îlot D", en S. Lancel, J.P Morel, J.P. Thuillier (eds.), Byrsa II. Mission Archéologique Française à Carthage. Roma, Collection de l'École Française de Rome 41: 85-103. Roma, École Française de Rome.
Marín, M.C. (2010): "Santuarios prerromanos de la costa atlántica andaluza", en T. Tortosa y S. Celestino (eds.), Debate en torno a la religiosidad protohistórica, Anejos de Archivo Español de Arqueologia LV: 491-534. Madrid, CSIC.

Merlin, A. y Drappier, L. (1909): "La nécropole punique d'Ard el Khéraïb à Carthage". Notes et documents publiés par la Direction des Antiquités, IV. París.

Ramon, J. (1995): Ses Païsses de cala d'Hort. Un establiment rural d'època antiga al sud-oest d'Eivissa. Quaderns d'Arqueologia Pitiüsa 1 (2a. ed.). Ibiza, Consell Insular d'Eivissa i Formentera.

Ramon, J. (2012a): "La cerámica púnico-ebusitana en época tardía (siglos III-I a.C.)”, en D. Bernal y A. Ribera (eds.), Cerámicas hispanorromanas II: 627661. Cádiz, Universidad de Cádiz.

Ramon, J. (2012b): "Perduraciones y cambios en las producciones cerámicas tardopúnicas en el extremo Occidente mediterráneo", en B. Mora y G. Cruz (coord.), La etapa neopúnica en Hispania y el Mediterráneo centro occidental: identidades compartidas: 223-258. Sevilla, Universidad de Sevilla.

Ramon, J. (e.p.): "La cerámica vascular de es Cuieram", en M.C. Marín (ed.), El santuario de Tinnit en la cueva de Es Culleram (Ibiza). Sevilla, Universidad de Sevilla.

Rodero, A. (1980): Colección de cerámica púnica de Ibiza. Museo Arqueológico Nacional 5. Madrid, Museo Arqueológico Nacional.

Tarradell, M. y Font, M. (1976): "Materiales púnicos de Ibiza en el museo de Lluc". Revista de la Universidad Complutense 25: 5-28.

Tarradell, M. y Font, M. (2000): Necrópolis rurales púnicas en Ibiza. Treballs del Museu Arqueolòic d'Eivissa i Formentera 45. Ibiza, Govern de les Illes Balears. Conselleria d'Educació i Cultura. 